\title{
O ENSINO DE BIOQUÍMICA E A PARTICIPAÇÃO DISCENTE NA PESQUISA: A PERSPECTIVA DOCENTE
}

Irani Ferreira da Silva ${ }^{1}$ \& Nildo Alves Batista ${ }^{2}$ Centro de Desenvolvimento do Ensino Superior em Saúde (CEDESS) - UNIFESP/EPM 1 irani@cedess.epm.br ${ }^{2}$ nbatista@cedess.epm.br

\section{Resumo:}

A Bioquímica é uma ciência que tem se desenvolvido de forma vertiginosa, tornando cada vez mais complexo o desafio de manter-se atualizado. A pesquisa na área tem se desenvolvido em vários institutos e, principalmente, no ambiente universitário que, teoricamente, deve propiciar experiências que motivem o aluno à produção de conhecimento, articulando ensino, pesquisa e extensão. Reconhecendo a importância do corpo docente para esta motivação, o objetivo deste trabalho é conhecer os professores responsáveis pelo ensino da Bioquímica nos cursos de graduação em saúde das universidades paulistanas, bem como os fatores que, na ótica destes docentes, incentivam os alunos à pesquisa. Os dados foram obtidos a partir de questionário aplicado aos professores e entrevista com uma amostra destes. Observamos um alto nível de titulação dos professores de Bioquímica dos cursos de graduação em Saúde das universidades paulistanas que se originaram de várias áreas de graduação. Esse nível de titulação acadêmica, a natureza do conhecimento bioquímico, as atividades práticas em laboratório, a contextualização do conteúdo com a futura prática profissional e o contato com professores pesquisadores em departamentos com sólida pesquisa em bioquímica são fatores descritos como incentivadores do interesse pela pesquisa pelo aluno.

Isto somente ocorrerá se a forma como o conteúdo for abordado estimular a construção ativa do conhecimento pelo aluno. A motivação docente para o desenvolvimento do espírito científico no aluno deve ser o eixo condutor do processo tornando-se necessário o desenvolvimento de políticas institucionais que propiciem uma melhor articulação ensino-pesquisa nos espaços de formação profissional.

\section{Abstract:}

Biochemistry is a science that is taking great steps forward, making the challenge of keeping a par of developments increasingly complex. Research in the area is undertaken in several institutes, especially in universities, where, in theory, the experience should motivate students to produce knowledge, coordinating teaching, research, outreach and extension. In recognition of the importance of the faculty in feeding this motivation, the goal of this study is to find out about the professors who teach biochemistry in the undergraduate courses on health taught in São Paulo's universities, as well as the factors that, in the view of these teachers, draw students towards research. Data was obtained from a questionnaire that the professors answered and interviews that were held with a sample group of the faculty. The professors of biochemistry were found to be highly qualified, coming from a variety of different academic areas. This academic level, allied to the nature of biochemistry itself, practical lab activities, the contextualization of the content with future professional activities and contact with professors engaged in research were the factors described as motivating interest in research on the part of the students. This can only take place if the way the content is presented encourages the active building of knowledge on the part of the student. The motivation of the teaching staff to develop their students' scientific thinking must be the main driving force, which means institutional policies must be put in place that lead to a better coordination of teaching and research activities in the professional education environment. 


\section{Introdução}

O conhecimento da bioquímica tem sido construído historicamente a partir da pesquisa. A construção desse corpo de conhecimentos possibilita a compreensão de vários fenômenos biológicos, podendo ser aplicado a outras ciências, como Medicina, Agronomia, Microbiologia, Nutrição, dentre outras $[1,2]$

A Bioquímica é uma ciência que tem se desenvolvido de forma vertiginosa, tornando cada vez mais complexo o desafio de manter-se atualizado.

Segundo Stryer [3]:

"Esta é uma época maravilhosa na Bioquímica. A tecnologia de DNA recombinante, a química de proteínas e biologia estrutural se juntaram para revelar os mecanismos moleculares dos processos biológicos fundamentais. Muitos de nossos sonhos de há apenas poucos anos foram realizados." $(p . I X)$

A produção do conhecimento bioquímico tem se desenvolvido em vários institutos de pesquisa e, principalmente, no ambiente universitário. Na universidade, a pós-graduação stricto-sensu é um dos principais mecanismos que alavancam a pesquisa.

A inserção acadêmica na universidade se dá por meio da docência, entendendo a pesquisa indissociável da atividade de ensino.

O Relatório do XV Fórum de Pró-Reitores de Graduação das Universidades Brasileiras, no ano 2002, [4] ressalta o papel da pesquisa como um elemento constitutivo do processo formador nos vários momentos curriculares, sendo fundamental para o processo de aprender a aprender.

Para Demo [5] a pesquisa possibilita um "questionamento reconstrutivo" que inclui tanto aspectos ligados à articulação teoria e prática quanto a produção de inovações e consciência ética.

Minayo [6] comenta que é a pesquisa que alimenta e atualiza o ensino em relação á realidade do mundo articulando pensamento e ação.

O desenvolvimento científico e tecnológico tem provocado mudanças nas necessidades de formação profissional. A crescente complexidade tecnológica exige o desenvolvimento de competências como capacidade de análise e síntese, habilidade de resolução de problemas, rapidez na atuação, comunicação, habilidade de trabalhar em grupo, versatilidade no uso da linguagem, habilidade para enfrentar desafios, flexibilidade frente a mudanças e capacidade de auto-aprendizagem. Essa formação, antes de valorizar o conteúdo, valoriza o desenvolvimento de competências cruciais para a atuação profissional em um mercado em constante transformação [7].

A metodologia de ensino deve, assim, possibilitar ação e reflexão sobre a própria ação, propiciando a formação integral do estudante, através da articulação entre atividades de ensino, pesquisa e extensão. A compreensão das bases da pesquisa científica é um dos fatores que instrumentalizam o aluno para a futura prática profissional [8].

Reconhece-se a importância do trabalho docente para esta formação, mobilizando os alunos para o desenvolvimento do raciocínio científico e motivando-os à produção do conhecimento.

O objetivo deste trabalho é conhecer os docentes responsáveis pelo ensino da Bioquímica nos cursos de graduação em saúde das universidades paulistanas, bem como os fatores que, na ótica destes docentes, incentivam os alunos à pesquisa.

\section{Material e Métodos}

Foram investigados os 75 professores de Bioquímica responsáveis por 53 cursos de graduação em saúde (5626 alunos), oferecidos pelas 12 universidades paulistanas, 10 particulares e 2 públicas. A caracterização dos docentes quanto à idade, formação acadêmica na graduação e pósgraduação, titulação, tempo de docência e regime de trabalho foi obtida a partir do universo dos docentes por um questionário. Os dados relativos a inserção na docência e à relação entre o ensino de bioquímica e a produção de conhecimento foram obtidos a partir de entrevista com uma amostra de docentes, selecionados pelos seguintes critérios: um docente por instituição particular e dois por instituição pública (o docente chefe da disciplina, quando houvesse, ou o docente com maior carga horária na instituição; quando existiu mais de um docente com a mesma carga horária máxima, foi entrevistado aquele com maior tempo de docência na instituição). Para as instituições públicas, além do chefe de disciplina, foi selecionado mais um professor, através de 
sorteio simples. Assim, a amostra de entrevistados foi de 14 docentes, identificados como P1 a P14. Os professores pesquisados documentaram seu consentimento de participação no presente estudo por um termo de anuência. Os dados dos formulários foram tabulados e as entrevistas foram analisadas pela técnica de análise de conteúdo [9].

\section{Resultados}

Dos 75 docentes envolvidos com o ensino de bioquímica nas universidades paulistanas, 38 compõem o corpo docente de 2 universidades públicas, com total de 17 turmas distribuídas em 12 áreas de graduação em Saúde. São docentes que apresentam um único vínculo institucional, regime de trabalho em tempo integral e participação efetiva nos projetos de pesquisa de seus Departamentos.

Os outros 37 docentes respondem pelo ensino da Bioquímica de 76 turmas de 12 áreas de graduação em Saúde de universidades particulares. São, de maneira geral, docentes com vínculo em mais de uma instituição $(65 \%)$ e dedicação, predominantemente, às atividades de ensino.

A idade média dos docentes é de 44 anos, com predomínio de professores entre 41 e 50 anos (35\%)(Figura 1).

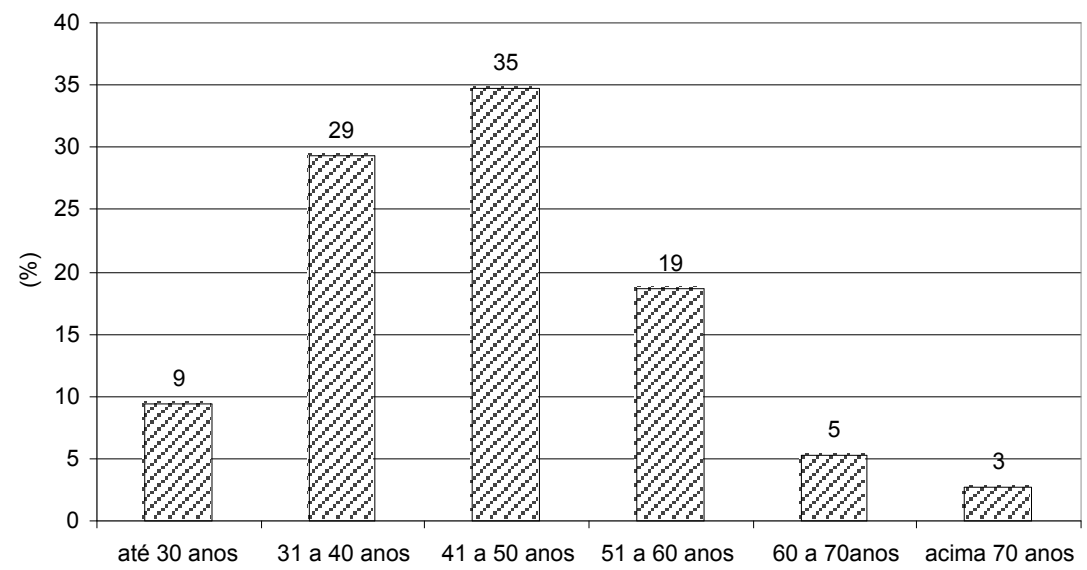

Figura 1: Distribuição etária dos professores de Bioquímica nos cursos de graduação em Saúde de universidades paulistanas.

O tempo médio de docência na disciplina de Bioquímica é de 14 anos, estando 30,7\% dos professores em fase inicial de carreira (0 a 5 anos - Figura 2).

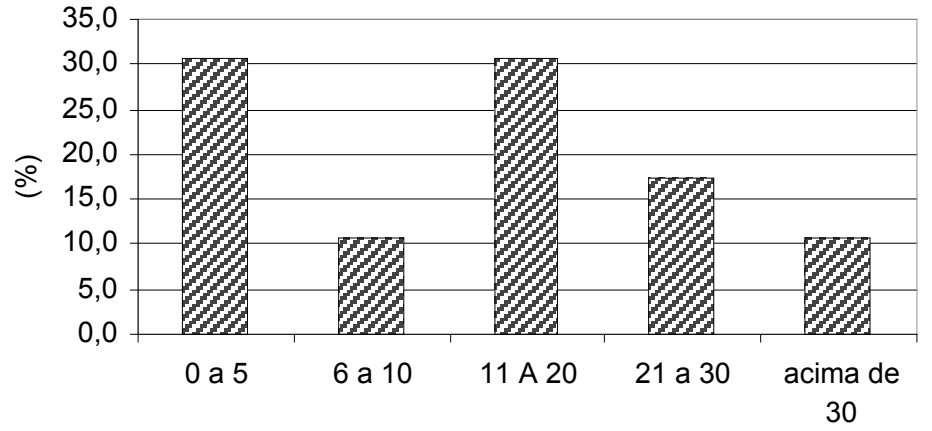

Figura 2 : Tempo de docência de professores de Bioquímica de cursos de graduação em Saúde das universidades paulistanas.

Esses profissionais foram graduados em variadas áreas de conhecimento, predominando Farmácia, Química e Biomedicina. Nota-se que $12 \%$ dos docentes não tiveram sua graduação na área da Saúde (Figura 3). 


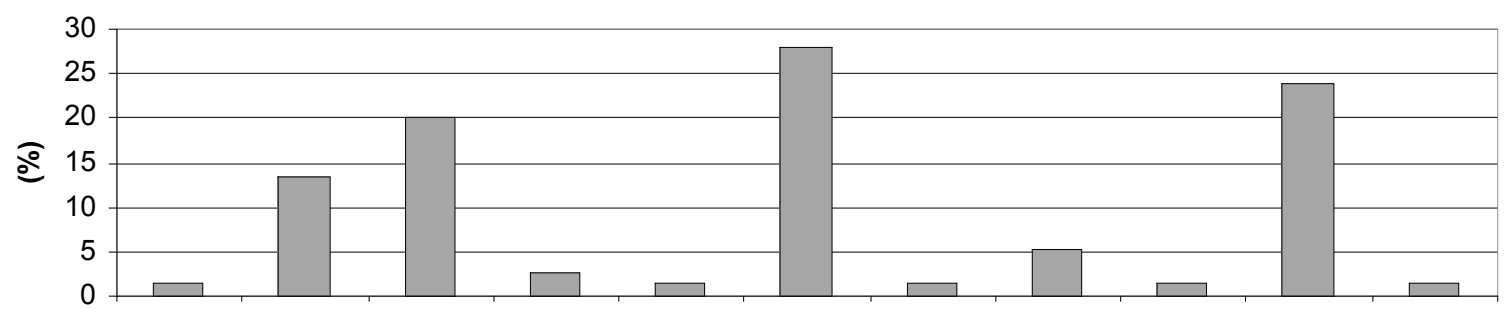

Figura 3: Área de graduação dos docentes de Bioquímica dos cursos de graduação em Saúde das universidades paulistanas.

Quanto à titulação acadêmica (Figura 4), 88\% dos docentes são mestres ou doutores. Entre os doutores, $46 \%$ são livre-docentes. Entre os docentes pesquisados, $63 \%$ dos especialistas estão cursando mestrado e $75 \%$ dos mestres, doutorado.

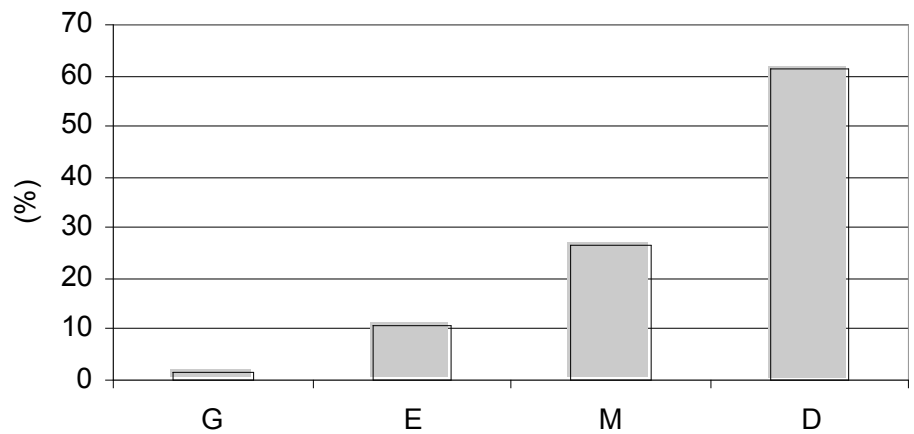

Figura 4: Formação acadêmica dos docentes de Bioquímica dos cursos de graduação em Saúde das universidades paulistanas.

( $G$ =graduação; $E=$ especilização; $M=$ mestrado e $\mathrm{D}=$ doutorado)

Observa-se uma heterogeneidade na área de titulação dos docentes, predominando Bioquímica, Biologia Molecular, Análises Clínicas e Ciências dos Alimentos (63\% - Figura 5).

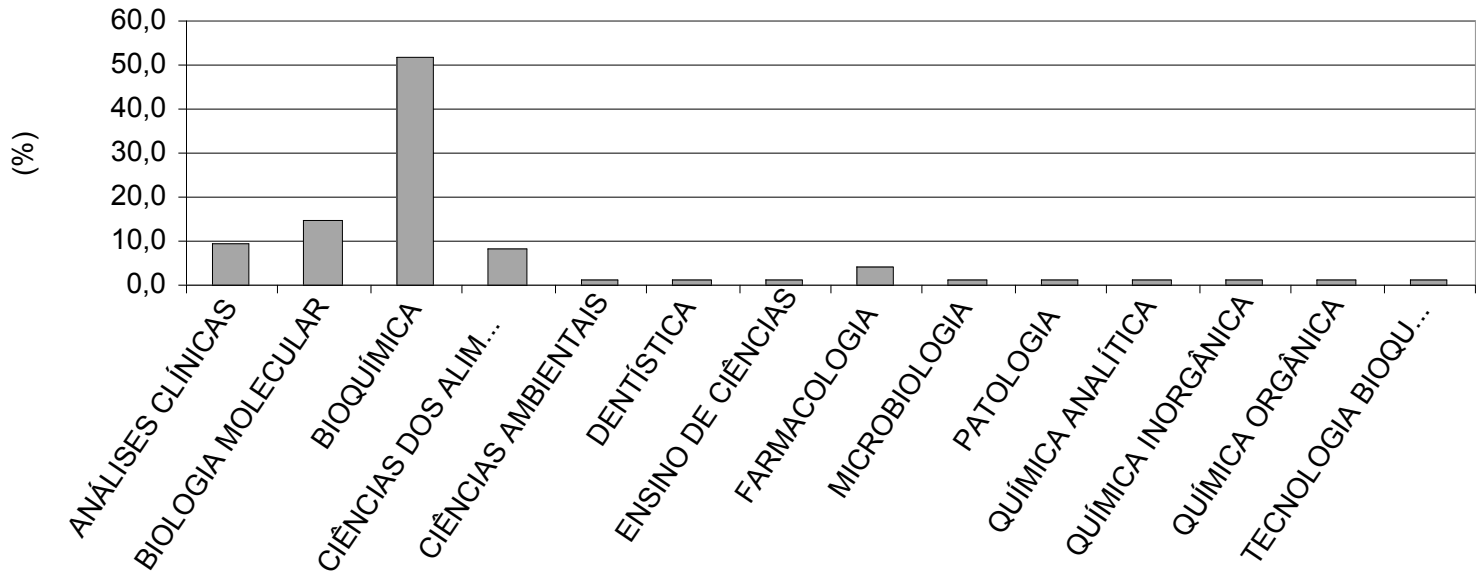

Figura 5: Área de titulação dos professores de Bioquímica dos cursos de graduação em Saúde das universidades paulistanas. 
A inserção destes docentes ocorreu por uma conjunção de fatores: o interesse específico pela Bioquímica na graduação, as atividades de monitoria desenvolvidas, a pós-graduação strictosensu, o interesse pela pesquisa e o interesse pela docência.

A própria característica da Bioquímica e o alto percentual de titulação acadêmica dos docentes envolvidos com o seu ensino na graduação deveria, teoricamente, incentivar os alunos para a pesquisa.

"...eu sempre abro um sorriso quando falo em pesquisa, falo que é estimulante. Sempre eu puxo minha sardinha um pouquinho, sempre. Porque eu gosto muito, acho legal..(P1)."

Em instituições onde a disciplina é vinculada a um departamento com sólido envolvimento com pesquisa, isso se revela de modo mais enfático:

"Como nós somos um departamento forte, temos um apreço pela produção do conhecimento, eu acho que isso é revelado nas nossas aulas e nas nossas atividades com os alunos (P8)"

Quanto aos aspectos desse ensino que atuam como possíveis mobilizadores do interesse do aluno pela pesquisa, um dos fatores citados foi a natureza do conteúdo que é base para a compreensão de outras disciplinas:

"Acho que por ser uma disciplina que é alicerce pra uma série de outras disciplinas, ela abre muita brecha pra pesquisa ...(P3)"

A ênfase no processo de elaboração do conhecimento bioquímico pode mobilizar o aluno para a pesquisa:

"Então se você conseguir acoplar a explicação do fenômeno em si com como você chegou nesse fenômeno você consegue estimular os alunos a entrar em uma iniciação científica, por exemplo. (P4)"

Outro fator mobilizador é a atividade prática em laboratório:

"Aqueles alunos que gostam das aulas de laboratório têm uma certa propensão a fazer pesquisa. ...(P6)"

Raw e Colli [10] acreditam que as aulas práticas devem ser utilizadas como uma estratégia para estimular nos alunos o raciocínio científico e a resolução de problemas. Criticam seu uso com o objetivo exclusivo de treinamento de técnicas, uma vez que essas se modificam rapidamente com os avanços da ciência.

A contextualização da bioquímica com a atuação do futuro profissional foi citada como um dos componentes motivadores:

"... O problema todo é você colocar situações. Por exemplo, na área de fisioterapia, você fala de condicionamento físico e outros processos. Como eu posso avaliar? Existem alguns parâmetros de medida, você pode medir ácido lático, você pode medir consumo de oxigênio...(P5)"

Os docentes também relacionam o interesse pela pesquisa como próprio do aluno:

" eu nem acredito que a gente semeie esse interesse, eu acho que a maioria já traz o interesse, alguns de uma forma mais exuberante, outros de uma forma mais velada mas isso já está neles. Especialmente na nossa área isso é muito fácil nesse momento porque a bioquímica tem atravessado um período de grande publicidade...(P8)"

O contato dos alunos com professores pesquisadores e o acesso aos laboratórios de pesquisa na faculdade também são importantes:

"Como este departamento tem uma vocação para a pesquisa muito, muito forte, o aluno tem contato com esses quarenta pesquisadores de renomado saber, que fazem basicamente $75 \%$ de seu tempo pesquisa básica ou aplicada na área das biológicas ou de saúde. Então eles têm o contato direto com esse pesquisador e algumas vezes eles entram até no laboratório do 
pesquisador. ....Então ele tem um contato muito grande com a pesquisa e é estimulado a pesquisar, a tomar contato com o que há de mais novo em pesquisa no mundo...P7)"

A atitude docente é também enfatizada:

"O que faz toda a diferença é o professor, se ele tiver um professor muito chato ele nunca vai querer ver bioquímica na vida. Se ele tiver um professor legal ele vai querer seguir os passos daquele cara que acaba sendo um modelo...(P12)"

\section{Discussão}

Alguns fatores presentes no ensino de bioquímica na graduação em saúde são motivadores para a iniciação científica dos alunos. Entre outros, destaca-se o perfil acadêmico dos docentes.

Observamos um alto nível de titulação dos professores de Bioquímica dos cursos de graduação em Saúde das universidades paulistanas ( $88 \%$ ), o que coloca em destaque este ensino em relação aos parâmetros atualmente desejados para o ensino superior no Brasil.

A Nova Lei de Diretrizes e Bases da Educação (LDB), no artigo 52 [11], caracteriza a universidade, entre outros aspectos, como instituição com, pelo menos, um terço do corpo docente com titulação acadêmica. Ao mesmo tempo, associa a formação do professor universitário com a pós-graduação.

O Ministério de Educação e Cultura na sua Avaliação das Condições de Oferta dos cursos de graduação em saúde considera que o nível mínimo de titulação para o ciclo básico deve se situar em 35\%, considerando-se "nível de excelência", 85\%.

Isto deve, naturalmente, articular o ensino com a pesquisa, motivando o corpo discente à produção do conhecimento.

Para isto, o tempo de dedicação docente é fator importante. Dedicação exclusiva e distribuição da carga horária em atividades de ensino e pesquisa ocorre para os docentes das universidades publicas.

Em instituições particulares, a grande maioria dos docentes tem seu vínculo e salários atrelados às atividades em sala de aula. Destes, $65 \%$ assumem um número maior de aulas vinculando-se a mais de uma instituição. Este fator dificulta o desenvolvimento de pesquisa pelos alunos.

Apesar da Bioquímica ser uma área de conhecimento fortemente vinculada à pesquisa, de ser um conhecimento necessário para a formação de profissionais de saúde e de existir a necessidade de se propiciar experiências de aprendizagem que valorizem a produção de conhecimento, este é um desafio para os docentes, especialmente das universidades particulares.

A tradição institucional em pesquisa possibilitando a convivência dos alunos com cenários de ensino-aprendizagem que estimulem a curiosidade e o raciocínio científico são, sem dúvida, fatores que motivam a participação discente na pesquisa.

No entanto, isto somente ocorrerá se a forma como o conteúdo for abordado estimular a construção ativa do conhecimento pelo aluno e estabelecer relação com a futura prática profissional. Para isto, a motivação docente para o desenvolvimento do espírito científico no aluno deve ser o eixo condutor do processo tornando-se necessário o desenvolvimento de políticas institucionais que propiciem uma melhor articulação ensino-pesquisa nos espaços de formação profissional.

É necessário ressaltar que o profissional do futuro precisa ser capaz de gerenciar seu próprio conhecimento, que se atualiza a partir da reflexão e do diálogo entre as pessoas que o produzem e aquelas que o utilizam [12].

Para Schanaider [13].

"O país precisa galgar um futuro promissor e, caso suas lideranças acadêmicas autênticas sejam capazes de manter infra-estrutura apropriada e se houver salários competitivos, a universidade terá condições de despertar o interesse dos futuros alunos para a pesquisa, pois estes, ao conviverem com os quadros docentes, irão entender que esta categoria atua com dignidade, logrando a tão almejada meta de realização profissional"( p. 68). 


\section{Referências Bibliográficas}

[ 1] R.E.Pinto; S.H. Marinho, in M.J. Halpern (Ed.) (1997) Bioquímica, Lidel Editora, Lisboa, pp. 13-23.

[ 2]P.C. Huang(2000) The integrative nature of biochemistry: challenges of biochemical education in the USA, Biochem. Educ. 28, 64-70.

[ 3] L. Stryer (1999) Biochemistry. 4th ed., W.H. Freeman and Company, New York, xxvii.

[ E]nsino de graduação: políticas, diretrizes e interfaces com a pesquisa e a extensão http://www.proacad.ufpe.br:8080/xvforgrad/documentos/carta de recife/carta de recife introducao $x$ $v$ forgrad.doc consultada em 2002.

[ 5] P. Demo (2000) Educar pela pesquisa. 40 ed Ed. Autores Associados, Campinas.

[ 6] M.C.S Minayo(org.)(2000) Pesquisa Social. Vozes, Petrópolis.

[ 7]A.Z. Kuenzer in: S.Castanho; M.E. Castanho (2001) Temas e textos em metodologia do ensino superior. Papirus, Campinas pp.15-28.

[ 8] N.A Batista; S.HS.S Batista(2001) O professor de medicina. Ed. Loyola, São Paulo.

[ 9]L. Bardin (1977) Análise de conteúdo. Edições 70, Lisboa.

[ 10] I. Raw; W. Colli (1972) Fundamentos de Bioquímica. EDART, São Paulo v. 1.

[ 11] BRASIL, Lei 9.394 de 20 de dezembro de 1996. Lei de Diretrizes e Bases da Educação Nacional.

[12] G. Schwartz (2000) As profissões do futuro. Publifolha, São Paulo.

[ 13] A. Schanaider (2002) Integração das Ciências Básicas e Áreas Profissionais no Ensino de Graduação em Medicina, Rev. Bras. Educ. Méd. 26, 67-70. 